\title{
A GLOBALIZAÇÃO DO AÇAÍ E SUA INFLUÊNCIA NAS PRÁTICAS AGRÍCOLAS DE CAMPONESES-RIBEIRINHOS DO BAIXO TOCANTINS
}

\author{
Renato dos Prazeres Rodrigues ${ }^{1}$ \\ (iD https://orcid.org/0000-0002-0480-0561 \\ Monique Medeiros ${ }^{2}$ \\ https://orcid.org/0000-0001-8789-0621
}

\section{RESUMO}

Objetivou-se, nesse artigo, compreender as relações entre as práticas de manejo empregadas nos açaizais por camponeses-ribeirinhos da Ilha Guajará de Baixo, Cametá-PA, e os canais de comercialização por eles acessados. Utilizou-se a pesquisa bibliográfica para aprofundamento no contexto histórico do extrativismo do açaí na Amazônia, entrevistas semiestruturadas e o instrumental metodológico de escalas de sombreamento em açaizais. A pesquisa envolveu agricultores de 16 Unidades de Produção Familiares-UPF e pautou-se na abordagem dos tipos de agricultura de Jan Douwe van der Ploeg. Os resultados revelam que a intensificação das práticas de manejo nos açaizais teve início em 2006, devido à maior demanda do fruto pelos mercados. Nas UPF caracterizadas com pouca sombra nos açaizais, todas as famílias acessaram o PRONAF e comercializam o açaí exclusivamente para intermediários. Em UPF com açaizais em escala de média sombra e muita sombra, predomina o tipo de agricultura camponesa e o acesso aos canais de comercialização: intermediário, feira e batedeiras. $\mathrm{O}$ fruto açaí em escala muita sombra apresenta melhor qualidade em relação aos demais e detém preferência das batedeiras, que ofertam o melhor preço na compra. Embora o acesso ao intermediário seja percebido como uma conquista para os camponesesribeirinhos, esse canal que se delineia guiado pela lógica dos Impérios Alimentares impulsiona as práticas de manejo intensivo nos açaizais e promove a interação com o tipo empresarial de agricultura. Verificou-se ainda que a pandemia da Covid-19 refletiu na dinâmica de venda, visto que a comercialização nas feiras foi interditada, permanecendo ativos os canais de comercialização das batedeiras e de intermediários.

Palavras-chave: Manejo de Açaizais, Tipos de Agricultura, Comercialização, Ilha Guajará de Baixo.

\section{THE GLOBALIZATION OF AÇAÍ AND ITS INFLUENCE ON THE AGRICULTURAL PRACTICES OF PEASANT-RIVERINE FARMERS IN LOWER TOCANTINS}

\begin{abstract}
The objective of this article was to understand the relationships between the management practices employed in the açaí groves by peasant-riverine farmers from Guajará de Baixo Island, Cametá-PA, and the commercialization channels accessed by them. The study used bibliographic research to deepen the historical context of the açaí extractivism in the Amazon, semi-structured interviews, and the methodological instrumental of shading scales in açaí groves. The research involved farmers from 16 Family Production Units-FPU and was based on Jan Douwe van der Ploeg's approach to types of agriculture. The results reveal that the intensification of management practices in the açaí groves began in 2006, due to increased demand for the fruit by the markets. In the FPU characterized with little shade in the açaí groves, all families have accessed PRONAF and market the açaí exclusively to middlemen. In FPU with medium shade and very shade scale açaí groves, the peasant farming type predominates, as well as the access to commercialization channels: intermediary, fair, and mixers. The açaí fruit in a very shady scale presents better quality than the others and is preferred by the

\footnotetext{
${ }^{1}$ Mestre em Agriculturas Familiares e Desenvolvimento Sustentável/UFPA. E-mail: renatoadp13.rr@gmail.com.

${ }^{2}$ Doutora em Agroecossistemas. Professora e Pesquisadora do Programa de Pós-Graduação em Agriculturas Amazônicas da Universidade Federal do Pará. E-mail: mmedeiros@ufpa.br.
} 
beaters, who offer the best price when buying. Although the access to the intermediary is perceived as an achievement for the riverine peasants, this channel, which is guided by the logic of the Food Empires, drives the intensive management practices in the açaí groves and interaction with the corporate type of agriculture. It was also found that the Covid-19 pandemic reflected on the sales dynamics, since the commercialization in the fairs was forbidden, and the commercialization channels of the mixers and intermediaries remained active.

Keywords: Management of Açaizais, Types of Agriculture, Commercialization, Guajará de Baixo Island.

\section{LA GLOBALIZACIÓN DEL AÇAÍ Y SU INFLUENCIA EN LAS PRÁCTICAS AGRÍCOLAS DE LOS CAMPESINOS RIBEREÑOS DEL BAJO TOCANTINS}

\section{RESUMEN}

El objetivo de este artículo fue comprender las relaciones entre las prácticas de manejo empleadas en las arboledas de açaí por los campesinos ribereños de la isla de Guajará de Baixo, Cametá-PA, y los canales de comercialización a los que acceden. Se utilizó la investigación bibliográfica para profundizar en el contexto histórico de la extracción de açaí en la Amazonia, las entrevistas semiestructuradas y el instrumento metodológico de las escalas de sombreado en las arboledas de açaí. La investigación contó con la participación de agricultores de 16 Unidades de Producción Familiar-UPF y se basó en el enfoque de Jan Douwe van der Ploeg sobre los tipos de agricultura. Los resultados revelan que la intensificación de las prácticas de gestión en los huertos de açaí comenzó en 2006, debido al aumento de la demanda de la fruta por parte de los mercados. En las UPF que se caracterizan por la escasa sombra en las arboledas de açaí, todas las familias accedieron al PRONAF y comercializan el açaí exclusivamente a intermediarios. En las UPF con plantaciones de açaí de escala media y muy sombra, predomina el tipo de agricultura campesina y el acceso a los canales de comercialización: intermediario, feria y mezcladores. La fruta de açaí en escala muy sombreada presenta mejor calidad que las demás y es la preferida por los batidores, que ofrecen el mejor precio al comprar. Aunque el acceso a los intermediarios se percibe como un logro para los campesinos ribereños, este canal, que se guía por la lógica de los Imperios Alimentarios, fomenta las prácticas de gestión intensiva en los huertos de açaí y la interacción con la agricultura de tipo corporativo. También se constató que la pandemia del Covid-19 se reflejó en la dinámica de ventas, ya que se prohibió la comercialización en ferias, quedando activos los canales de comercialización de los mezcladores e intermediarios.

Palabras clave: Gestión de los Açaizais, Tipos de Agricultura, Comercializacion, Isla Guajará de Baixo.

INTRODUÇÃO ${ }^{3}$

A Amazônia brasileira vem ganhando na contemporaneidade cada vez mais destaque nos debates políticos, sociais, econômicos e ambientais voltados para a gestão dos recursos naturais. A diversidade de fauna e flora nela presente está distribuída nos diversos ecossistemas que compõem o seu território: terra firme, igapó, savanas, várzeas, campos naturais, mangues, entre outros. Os ecossistemas de várzea do estuário amazônico ganham destaque nessa pesquisa justamente por serem

\footnotetext{
${ }^{3} \mathrm{O}$ artigo foi originalmente construído como parte dos resultados da dissertação intitulada: “Tem coisa melhor que vender açaí?”: os passos e percalços na expansão dos açaizais na várzea do Baixo Tocantins, defendida junto ao Programa de Pós-Graduação em Agriculturas Amazônicas (PPGAA/UFPA), em setembro de 2021.
} 
predominantemente povoados por camponeses-ribeirinhos (Cruz, 2007; Pereira; Witkoski, 2012). Para os autores supracitados, os ribeirinhos amazônicos possuem traços oriundos do campesinato, provenientes do povoamento do estuário amazônico, que são intrínsecos ao seu modo de vida, e, por isso, mesmo sendo conhecidos como ribeirinhos por morarem à margem dos rios, em suas origens não deixam de ser camponeses.

Essa categoria de povos tradicionais da Amazônia, que residem à margem dos rios e igarapés, e mantêm constantes relações com o capital, por intermédio do acesso a mercados formais para excedentes produtivos provenientes das estratégias de diversificação em suas UPF, se diferencia das demais pelo seu peculiar modo de vida afetivamente ligado ao ambiente aquático, e conhecimento aprofundado dos ecossistemas de terra firme e várzea (Silva; Malheiro; Ribeiro, 2005; Cruz, 2007; Pereira; Witkoski, 2012; Corrêa, 2014).

Por meio dos conhecimentos contextuais adquiridos ao longo da vida, os camponesesribeirinhos manejam os recursos naturais a fim de alcançarem benefícios comuns e/ou coletivos. Esses conhecimentos permitem múltiplas interações com o ecossistema e uma variedade de estratégias para a produção e reprodução do núcleo familiar, construídas pela família a partir da diversidade produtiva (Mendonça et al., 2007; Cruz, 2007). Sobrinho (2005) destaca que nas várzeas da região do Baixo Tocantins há uma riquíssima diversidade de espécies frutíferas.

No entanto, a espécie que mais ganha expressividade no estuário ribeirinho, atualmente, é o açaí. Não mais apenas por sua importância como a principal fonte de alimento, mas também como geradora de renda. Nas décadas de 1970 a 1980, no Baixo Tocantins, intensificou-se o interesse pelo extrativismo do palmito de açaizeiros nativos. Segundo Sobrinho (2005) e Homma et al. (2006), a prática predatória dessa atividade foi tão significativa que comprometeu o estoque de frutos para $\mathrm{o}$ autoconsumo, levando o presidente Ernesto Geisel a assinar a Lei n ${ }^{\circ} 6.576 / 1978$, proibindo a extração do palmito em todo o território nacional.

Assim, a extração predatória do palmito de açaizeiro foi perdendo força a partir da década de 1990. Devido à fiscalização por órgãos competentes, muitas agroindústrias de palmito que funcionavam de maneira clandestinas foram fechadas. Mesmo com a restrição da exploração do palmito, os açaizais ainda continuaram sendo de significativo interesse dos camponeses-ribeirinhos, mas, nos últimos anos, o principal produto de interesse proveniente dessa espécie vegetal vem mudando.

No estado do Pará, anterior à década de 1990, a produção de açaí era basicamente voltada para o autoconsumo familiar e abastecimento do mercado interno (Corrêa, 2017). No atual cenário, a polpa do fruto e os seus subprodutos passaram a ser consumidos a nível nacional e internacional, motivando uma alta demanda. Essa nova realidade motivou distintos camponeses-ribeirinhos na expansão dos açaizais e do emprego de práticas de manejo para um possível aumento da produção e produtividade 
do fruto. Segundo Homma et al. (2006), as palmeiras de açaizeiros tornaram-se as principais espécies vegetais presentes no ecossistema de várzea no Baixo Tocantins, com maior concentração de açaizais manejados no estuário dos rios Tocantins, Pará e Amazonas.

Em Cametá, a produção agroextrativista de açaí é a atividade mais influente nas várzeas do município, sendo o segundo maior produtor do Estado do Pará. Entre os anos de 2018/2019, essa atividade representou $51 \%$ da produção agrícola municipal, o equivalente a 159.450 toneladas do fruto (PAM/IBGE, 2020). No lócus de pesquisa, na Ilha Guajará de Baixo, em Cametá, os efeitos da valorização econômica do açaí são percebidos de formas diversas e são também relacionados pelos camponeses-ribeirinhos como impulsionadora da melhoria de qualidade de suas vidas.

No entanto, as consequências da globalização do açaí e da alta procura dos mercados pelo fruto vêm se materializando na intensificação do manejo dos açaizais nas Unidades de Produção Familiar (UPF). O modo intensivo de manejo tem provocado a perda da biodiversidade, principalmente de espécies florestais vistas pelos camponeses-ribeirinhos como sem valor econômico, improdutivas e impróprias de se estabelecerem junto aos açaizais (Araújo; NavegantesAlves, 2015). Diante desse contexto, objetivou-se compreender as relações entre as práticas de manejo empregadas nos açaizais por camponeses-ribeirinhos da Ilha Guajará de Baixo, Cametá-PA e os canais de comercialização acessados por esses camponeses-ribeirinhos. A escolha do lócus se deu devido ao acelerado processo de expansão dos açaizais no estuário ribeirinho, a partir do ano 2006, quando intermediários representantes de agroindústrias processadoras de açaí passaram a adentrar a comunidade para a compra do fruto.

\section{ETAPAS E PROCEDIMENTOS METODOLÓGICOS}

A mobilização teórica iniciou-se com a pesquisa bibliográfica, por meio da qual foram selecionados artigos científicos relativos às etapas históricas dos ciclos de atividades econômicas no Baixo Tocantins, em especial o açaí. As idas a campo que configuraram a etapa de construção de dados primários ocorreram entre os meses de agosto e dezembro de 2020, na Ilha Guajará de Baixo, Cametá, respeitando as orientações de biossegurança da Organização Mundial da Saúde- OMS, em virtude da pandemia da Covid-19. Para se chegar aos interlocutores, foi utilizada a técnica da "bola de neve" (Baldin; Munhoz, 2011), na qual os informantes-chave foram os intermediários de açaí agroextrativista em Guajará de Baixo. Estiveram envolvidos na pesquisa 8 (oito) camponesesribeirinhos que comercializam o açaí em maior quantidade e frequência, e 8 (oito) que comercializam em menor quantidade e frequência. As entrevistas aconteceram face-a-face, entre pesquisador e camponês-ribeirinho. O caderno de campo e a gravação, após concordância dos participantes, auxiliaram no registro das informações (Michelat, 1987). Os conteúdos orais das entrevistas foram 
transcritos na íntegra para compor os trechos das falas dos camponeses-ribeirinhos, mantendo o anonimato dos entrevistados.

Apoiando-se no instrumental metodológico de escalas de sombreamento de uma cultura principal, em consórcio com outras árvores, como proposto por Gonzáles (2006), foi possível construir um instrumental adaptado à cultura do açaí, no qual foram consideradas as seguintes escalas de sombreamento: sem sombra (açaizais em sistema de monocultivo); pouca sombra (escala de sombra das espécies florestais sobre os açaizais entre 10 e 25\%); média sombra (escala de sombra das espécies florestais sobre os açaizais entre 30 e 45\%); e muita sombra (escala de sombra das espécies florestais sobre os açaizais superior a 50\%). Após explicação aos entrevistados sobre o instrumental metodológico, os camponeses-ribeirinhos indicavam a atual escala de sombreamento de seus açaizais.

\section{OS TIPOS DE AGRICULTURA E SUAS CONFIGURAÇÕES EM TORNO DA GLOBALIZAÇÃO DO AÇAÍ}

Segundo Ploeg (2008), a agricultura vem sendo praticada no mundo de maneiras e princípios diversos, entretanto, percebe-se três tipos mais expressivos de agricultura, em constante interação e influência: agricultura capitalista, agricultura empresarial e agricultura camponesa. Para Ploeg (2008), a principal diferença entre os três tipos de agricultura é observa na escala em que são aplicados. A agricultura camponesa representa unidades de produção pequenas e vulneráveis, centradas na família, e com certo distanciamento dos complexos agroindustriais, o que a torna secundária sob a perspectiva do regime hegemônico de produção. No lado oposto, encontra-se a agricultura capitalista, com elevado uso de insumos, grande escala, forte e importante na produção de commodities. A situação intermediária mescla trabalho familiar com elevado emprego de tecnologias e é representada pela agricultura empresarial, a qual pode compreender tanto unidades produtivas pequenas quanto grandes. Nesse pressuposto, a amplitude dos simples aos mais complexos sistemas de cultivos agrícolas podem ser analisados pelo viés dos tipos de agricultura evidenciados por Ploeg (2008).

Ploeg $(2006 ; 2008)$ revela que a agricultura capitalista se interliga mundialmente por redes de empresas agrícolas, centradas na produção de lucros, mesmo que isso implique a redução do valor agregado. A agricultura empresarial, por sua vez, consolidou-se no mundo entre as décadas de 60 e 70, no período da Revolução Verde, advinda da ideia de modernização da agricultura, para o desenvolvimento e "progresso" com a introdução dos pacotes tecnológicos. Esse tipo de agricultura centraliza sua base nos recursos externos e é voltada ao aumento da escala produtiva para o constante acesso dos agricultores aos mercados, visando a eficiência econômica. 
Já a agricultura camponesa, para Ploeg (2008), se destaca por envolver diretamente o núcleo familiar no gerenciamento da unidade de produção, bem como no trabalho empregado nas etapas produtivas. Nesse tipo, a relação de reciprocidade entre parentes, amigos e vizinhos ganha expressividade, e a coprodução da sociedade-natureza também se beneficia dessa relação (Ploeg, 2006, 2008; Schneider; Niederle, 2008; Medeiros, 2017).

Ademais, o autor também mobiliza a relação dos três tipos de agricultura com os mercados de comercialização da produção. A agricultura camponesa centraliza-se na construção e reprodução de circuitos curtos de circulação de mercadorias, nos mercados locais. Enquanto a agricultura capitalista e empresarial relaciona-se com escalas macros, vinculadas a empresas a nível mundial e produtos de interesses empresariais, definidos como Impérios Agroalimentares (Ploeg, 2008). Quanto mais se intensifica a artificialização da produção, com a dependência de insumos externos e do acesso aos mercados de cadeia longa, mais tende o agricultor a se aproximar do tipo de agricultura capitalista ou empresarial (Ploeg, 2008). Nesse caso, o agricultor tem sua autonomia reduzida, e distancia-se do princípio camponês de coprodução, importante para manter a capacidade de reprodução social.

$\mathrm{Na}$ agricultura capitalista e empresarial, a incessante demanda dos mercados globais por produtos de interesse agroindustrial configura um sistema agrícola de produção em massa, com baixa diversificação, e grandes extensões de monocultivos agrícolas (Ploeg, 2008). Para Rosset e Altieri (1997), esse tipo de sistema de produção torna-se insustentável ao logo do tempo, uma vez que se materializa em sucessões constantes de degradação dos recursos do ecossistema. De modo diferente, na agricultura camponesa, os recursos do ecossistema se perpetuam por mais tempo, havendo menor prejuízo ambiental (Petersen; Dal Soglio; Caporal, 2009).

Na concepção de Ploeg (1992), a inserção dos camponeses aos canais de comercialização, sobretudo os de cadeia curta, não causa ruptura total do seu modo de vida, mas o acesso tende a fortalecer as bases internas de produção e garante autonomia nas UPF. Nesse caso, no acesso aos circuitos curtos de comercialização, como as feiras agroecológicas, as feiras de produção familiar, ou o mercado institucional ${ }^{4}$, o camponês escapa do controle direto do capital (Schneider; Niederle, 2008). Mas, como a construção dessas estratégias é dinâmica, o acesso a distintos mercados vai ganhando roupagens diferentes, a depender dos interesses e necessidades dos camponeses.

Segundo Cruz (2007), o camponês-ribeirinho do estuário amazônico, que acessa os mercados de circuitos longos para a comercialização de seus principais produtos agroextrativistas, possui forte ligação com grupos dominantes. Para Corrêa (2014), os grupos dominantes no Baixo Tocantins são empresários, comerciantes, intermediários, cooperativas, etc., que percorrem o estuário para a compra

\footnotetext{
${ }^{4}$ Mercado que engloba as compras governamentais de alimentos para serem utilizados em programas e organismos públicos, tais como alimentação escolar, hospitais, presídios, entre outros (Real; Schneider, 2011, p. 58).
} 
principalmente do fruto açaí, prática mais fortemente presente a partir da década de 2000. Nesse contexto, a relação estreita de alguns camponeses-ribeirinhos com os Impérios Alimentares, materializados pelos grupos dominantes acima mencionados, vem os aproximando do tipo de agricultura empresarial e, consequentemente, influenciando na intensidade de manejo na UPF, no contexto analisado.

\section{OS AÇAIZAIS NA ILHA GUAJARÁ DE BAIXO}

Na Ilha Guajará de Baixo, a produção de açaí sempre fez parte do contexto das famílias camponesas-ribeirinhas. Os anciões afirmam que, desde antes do início do extrativismo do palmito, houve interesse pela extração do fruto açaí, que era praticada de modo extrativista até a década de 1990. Tinha como principal finalidade o autoconsumo familiar. O suco do fruto, conhecido localmente como "vinho do açaí", juntamente com o peixe e a farinha de mandioca, já eram os principais componentes na dieta alimentar dos camponeses-ribeirinhos (Sobrinho, 2005).

Os camponeses-ribeirinhos que vivenciaram anos posteriores à década de 1990 mencionam a dificuldade para vender o excedente produtivo de açaí durante a safra. Devido à comercialização concentrar-se exclusivamente nas feiras das vilas Porto Grande e Carapajó, circunvizinhas à Guajará, havia uma alta oferta do fruto para baixa demanda, consequentemente, o açaí tinha pouco valor econômico. A venda do palmito do açaizeiro era a atividade extrativista mais expressiva proveniente dos açaizais, como menciona o entrevistado:

\footnotetext{
Nos anos de 1980, 1990, me recordo que o açaí não tinha valor de venda. Era vendido uma vez por outra na vila aqui perto de casa [Carapajó e Porto Grande], mas o preço era muito barato, o equivalente a $\mathrm{R} \$ 2,00,3,00$ a lata [14kg] (Camponês-ribeirinho, 63 anos, Guajará de Baixo, Cametá-PA, dez/2020).
}

Logo, algumas famílias coletavam o fruto do açaí apenas para o autoconsumo, outras praticavam a troca do açaí in natura por farinha de mandioca, com parentes ou amigos que moravam em ecossistema de terra firme e dedicavam-se ao cultivo de roças para a produção de subprodutos da mandioca. Na entressafra do açaí (janeiro a junho), a escassez de produção do fruto interferia na segurança alimentar das famílias, que conviviam com a falta do açaí apropriado para o consumo. Assim que o açaí iniciava o estado de maturação (açaí “parau”), era colhido para a extração do "vinho", que dava uma coloração esverdeada e com sabor atípico, mesmo assim consumido.

Os açaizais de $100 \%$ dos entrevistados, anteriormente a 1990, localizavam-se somente no entorno das residências. Na safra (agosto a dezembro), a produção de açaí supria a demanda para o autoconsumo, não havendo necessidade em aumentar a produção. Predominava o extrativismo, em sistema extensivo, conforme observa o entrevistado: 
O açaizal da minha família correspondia uma área de $20 \%$ da propriedade, o restante era mata, pois o açaí não tinha valor econômico, a gente acabava valorizando outras coisas, como a madeira na intenção de vender as toras e não se preocupava muito com o açaizal (Camponês-ribeirinho, 43 anos, Guajará de Baixo, Cametá-PA, ago/2020).

O açaí, antes visto como alimento dos pobres (Brondízio, 2008), passou, então, a ganhar expressividade no Império Alimentar. No cenário nacional, a polpa de açaí se destaca a partir de 1990, quando os estudos científicos comprovaram os benéficos nutricionais do fruto, desde então o açaí passou a ter maior visibilidade no país, o suco passou a ser consumido em todos os estados brasileiros e por todas as classes sociais (Corrêa, 2014). No contexto internacional, a demanda por polpa de açaí teve início na década de 2000, tornando-se um produto em acessão nos mercados globais, sendo consumido pelos habitantes mundo afora, misturado com outros produtos conhecido como Mix, assim como utilizado na fabricação de subprodutos (Brondízio, 2008).

A partir do ano 2000, instalaram-se nas vilas de Porto Grande e Carapajó as primeiras batedeiras de açaí em estabelecimentos onde se manipula o fruto para a retirada da polpa. A produção do açaí de Guajará de Baixo deixou de ser exclusivamente realizada nas feiras e passou também a acontecer nas batedeiras. Embora pelas batedeiras fosse comprada uma quantidade expressiva, o desperdício do fruto ainda era significativo, e o preço auferido por lata ${ }^{5}$, no valor máximo de R\$ 10,00, desmotivava os camponeses-ribeirinhos. Mas, em meados de 2006, na Ilha Guajará de Baixo, configura-se um novo cenário para a comercialização do açaí. As agroindústrias processadoras da polpa do fruto emergem como um novo mercado. A partir da safra do açaí de 2006, intermediários representantes de agroindústrias instaladas no estado do Pará iniciaram os primeiros percursos na Ilha para a compra do fruto.

Constatou-se, em 2021, a presença de sete intermediários que atuavam na compra do açaí na Ilha, especialmente nos meses de agosto a dezembro, correspondente ao período da safra. As latas de açaí compradas na Ilha Guajará são conduzidas para os caminhões das agroindústrias que aguardam pelos intermediários, no porto da balsa, situado na vila de Carapajó, próximo à margem do rio Tocantins e com acesso a PA-469, que interliga a vila à PA- 151. Tal processo permite a condução rodoviária da produção de açaí do município de Cametá às agroindústrias situadas nos municípios paraense como: Igarapé-Miri, Abaetetuba, Mocajuba, Tomé-Açu, Castanhal e Benevides.

Todos os entrevistados afirmaram que, a partir da entrada dos intermediários para a compra do açaí, a comercialização do fruto foi facilitada devido à demanda incessante de açaí agroextrativista por esse canal de comercialização. Ademais, constatou-se que os intermediários se preocupam mais em obter elevada quantidade de fruto do que frutos com elevada qualidade. Segundo os entrevistados que comercializam para o intermediário, esses compram o açaí de aparência física avermelhada no

\footnotetext{
${ }^{5}$ Unidade de medida correspondente a $14 \mathrm{~kg}$, utilizada para a comercialização do açaí fruto.
} 
início da safra, e no final da safra os frutos são comercializados com a aparência física "moqueada", ou seja, "frutos que foram colhidos em dias anteriores ou ocorreu a demora no transporte e começou a secar" (Homma et al., 2006, p. 13).

Por meio da intensiva atuação significativa dos intermediários, a Ilha vivenciou o auge da valorização econômica do fruto, pois estes passaram a comprar todo o excedente produtivo local. Isso motivou as famílias na expansão dos açaizais, com o emprego de técnicas distintas de manejo. Em decorrência disso, o ecossistema de várzea da Ilha Guajará de Baixo vem sofrendo drásticas mudanças no que se refere à composição vegetal.

\section{RELAÇÕES ENTRE TIPOS DE AGRICULTURA E ESCALAS DE SOMBREAMENTO NOS AÇAIZAIS}

Grossmann et al. (2004), Santos, Sena e Homma (2012), Araújo e Navegantes-Alves (2015) e Azevedo (2010), ao pesquisarem manejo de açaizais de várzea no estuário amazônico, constataram quatro tipos de manejo: intensivo, semi-intensivo, moderado e semimoderado. Para os mesmos autores, o que muda em cada tipologia de manejo é a intensidade das práticas empregadas, que se relacionam diretamente com a quantidade de espécies florestais em consórcio com os estipes de açaizeiros por hectare, e, por conseguinte, influencia na escala de sombreamento dos açaizais. Em Guajará, constatou-se as escalas de sombreamento: pouca sombra, média sombra e muita sombra, que também estão correlacionadas com os tipos de manejo: semi-intensivo, moderado e semimoderado.

Os açaizais com sombreamento moderado foram os mais constatados (50\%), seguidos pelos açaizais com pouca sombra (31\%) e com muita sombra (19\%). Em nenhuma UPF foi encontrado açaizais sem sombreamento. Ressalta-se que as práticas de manejo empregadas pelos camponesesribeirinhos foram mencionadas pela maioria dos entrevistados (75\%) como sendo pautadas exclusivamente no conhecimento contextual, enquanto os demais entrevistados (25\%) mencionaram receber assistência de técnicos de cooperativas, associações e bancos na configuração das práticas de manejo. Os conhecimentos contextuais, estes adquiridos e acumulados ao longo da vida, possibilitam aos camponeses-ribeirinhos múltiplas interações com o ecossistema, e permite-lhes planejar e executar estratégias de produção e reprodução do núcleo familiar (Mendonça et al., 2007).

Segundo Araújo e Navegantes-Alves (2015), as práticas no manejo do açaizal, pouco têm se modificado ao logo do tempo, contudo, a intensidade e frequência delas é que sofreram alteração. Nos açaizais em sombreamento moderado, as famílias realizam o desbaste das touceiras, e, fazendo a seleção das mais sadias e produtivas, fica, em média, 5 estipes por touceiras. Também são retiradas as árvores que causam sombreamento excessivo, e algumas sem valor econômico. No enriquecimento do açaizal, pratica-se principalmente a semeadura a lanço, o transplantio de mudas nativas e o manejo 
de estipes juvenis provenientes da regeneração natural. As roçagens acontecem duas vezes por ano, no último mês que antecede a safra (julho) e final da safra do açaí (dezembro), com mão de obra basicamente familiar, ou com troca de dias de trabalho com os vizinhos.

Nos açaizais com pouca sombra, no manejo, retira-se os cacaueiros nativos, pois, para as famílias, o consórcio desse vegetal com os açaizeiros reduz a produtividade do açaí. Outras espécies florestais também são retiradas do sistema devido à mesma justificativa. Deixa-se poucas espécies madeireiras, como a andirobeira (Carapa guianensis Aubl.) e a ucuúbeira (Virola surinamensis Warb.). As touceiras constituem-se por no máximo quatro estipes, e a roçagem do açaizal acontece, pelo menos, três vezes ao ano, por roçadores que são pagos com diárias. Esses roçadores eliminam as espécies de estratificação baixa, como cipós, jacitaras (Desmoncusorthacanthus Mart.) e arumãs (Ishnosiphon Ovatus), sendo esses dois últimos importantes matérias-primas para a confecção de utensílios artesanais. O enriquecimento do açaizal dá-se por semeio a lanço, transplantio de mudas nativas e variedades melhoradas da Empresa Brasileira de Pesquisa Agropecuária (EMBRAPA).

Já nos açaizais com muita sombra, a roçagem é realizada uma vez por ano, com mobilização da mão de obra familiar ou troca de dias de trabalho. Permanece de 5 a 6 estipes de açaizeiro por touceiras, sem espaçamento definido. Além do açaí, prioriza-se os arumãs, jacitaras e demais espécies vegetais madeireiras e não-madeireiras que são mantidas até que seja necessário retirá-las para a produção de lenha ou madeira. O enriquecimento dos açaizais constitui-se do manejo das plantas juvenis de regeneração natural, ou pelo semeio a lanço das sementes de açaí. Segundo os camponesesribeirinhos, não se aplica o transplantio por mudas devido ao desenvolvimento do vegetal para a produção do fruto ser mais lento em comparação aos tipos de enriquecimento a lanço e manejo dos estipes juvenis.

A adoção de práticas distintas de enriquecimento dos açaizais empregadas pelas famílias em suas UPF pode ser relacionada com sua maior ou menor aproximação com os tipos de agricultura camponesa e empresarial. Nas UPF em que se pratica o enriquecimento através do manejo dos estipes de regeneração natural, há a produção em maior escala de sombra. Esse enriquecimento realizado em tais UPF pode ser compreendido como mais conectado ao tipo camponês de agricultura. Já nas UPF nas quais o camponês-ribeirinho recorre às sementes melhoradas da EMBRAPA, desenvolvidas para o cultivo em ecossistema de terra firme, estas necessitam, necessariamente de acompanhamento técnico no manejo da espécie em várzea, assim como de insumos externos, tendo em vista que há uma maior vinculação ao tipo empresarial de agricultura. As variedades de açaí BRS utilizadas para terra firme são altamente dependentes de adubação química balanceada (Homma, 2012). Entretanto, é preciso enfatizar que, segundo Ploeg (2008), as práticas distintas adotadas pelas famílias são consideradas movimentos dinâmicos. Desse modo, o camponês-ribeirinho, produtor de açaí, para 
alcançar os projetos de vida ou anseios das famílias, pode empregar estratégias nas práticas de manejo, ora articuladas ao tipo de agricultura camponesa, ora empresarial.

Segundo Ploeg (2009, p. 2), uma das diferenças entre o tipo de agricultura camponesa e o tipo empresarial é a concepção da relação sociedade-natureza. Enquanto a agricultura camponesa "é fortemente baseada no capital ecológico da natureza viva", o modo empresarial "afasta-se progressivamente da natureza". Essa relação pode ser observada nas práticas de manejo empregadas nos açaizais quanto às escalas de sombreamento. Nos açaizais com sombreamento moderado e com muita sombra, existe forte preocupação dos camponeses em conciliar os componentes da natureza com a produção de açaí. Essa coprodução do social com o natural é decisiva na obtenção de níveis mais elevados de produtividade e autonomia, sem a necessidade de recorrer a insumos externos. Por conseguinte, é possível dizer que essa materialização de práticas se vincula ao tipo de agricultura camponesa.

Nos açaizais com pouca sombra, prioriza-se o açaí, desconsiderando as outras espécies vegetais, o que leva, consequentemente, a uma dependência das famílias a um único produto e a uma maior pressão no ecossistema para se chegar à produtividade desejada. Nesse caso, é possível verificar a presença do tipo de agricultura empresarial.

A coprodução torna-se mais evidente nos açaizais com muita sombra, justamente porque nesses sistemas as famílias mantêm a diversificação vegetal e reduzem a frequência e intensidade da roçagem anual. Assim, a "natureza viva” oferece-lhes produtos diversos, tais como: alimentos, fibras, madeira, dentre outros relacionados ao seu maior alcance de autonomia. Segundo Ploeg (2009, p. 4), essa base de recursos autogerida pelas famílias envolve tanto recursos sociais como naturais, moldados para "comportar, tanto quanto possível, os interesses e as expectativas da família camponesa".

Mobilizando as reflexões de Ploeg (2003), é possível alegar que os diferentes tipos de manejo podem se materializar como possíveis estratégias de resistência a algum tipo de processo homogeneizante de desenvolvimento fomentado pelo Império, ou mesmo por sua retroalimentação. Dessa forma, a condução de um sistema diversificado, a escolha por determinadas práticas de sombreamento e o acesso a canais de comercialização de cadeia curta podem ser constituídas como estratégias de enfrentamento ao formato homogeneizante proposto pela lógica do Império. Assim como a redução da diversificação de espécies nas UPF, e tendência ao monocultivo e acesso aos canais de comercialização de cadeia longa podem ser compreendidos como formas de retroalimentação desse Império.

A escolha dos canais de comercialização a serem acessados para a comercialização do açaí tem relação intrínseca com os espaços de manobra construídos e aproveitados pelos camponesesribeirinhos. Na pesquisa, evidenciou-se a presença do intermediário nos processos de comercialização 
do açaí nos beiradões ${ }^{6}$, praticados por $100 \%$ dos entrevistados. A maioria (78\%) acessa os três tipos de canais de comercialização, 16\% acessam exclusivamente os intermediários e 6\% mantêm vínculo com o intermediário e batedeiras. Entretanto, os "espaços de manobra" desses camponesesribeirinhos ganham configurações nas feiras e nas batedeiras, pois há maior barganha de preços e construção de laços de amizades e confiabilidade entre vendedor e comprador.

Ainda que tal intermediação nos processos de comercialização implique a menor autonomia dos camponeses-ribeirinhos e eles reconheçam isso, obstáculos para a venda da produção em canais de comercialização que não exigiriam essa intermediação afastam alguns desses camponeses. Os obstáculos verificados foram: exigência de uma boa aparência e qualidade física do fruto, tempo disponível para a condução da produção aos locais de venda, incerteza de comercialização, entre outros.

Constatou-se que todos os camponeses-ribeirinhos que possuem açaizais com pouca sombra acessaram o Programa Nacional de Fortalecimento da Agricultura Familiar (PRONAF) para a expansão dos açaizais, entre os anos de 2000 a 2008. Essas famílias, que não tinham condições de pagarem diárias para os operadores de motosserra fazerem a derrubada da vegetação nas UPF e consequente implantação dos açaizais, por meio do acesso a esse crédito, investiram parte do recurso nessa atividade.

Para os camponeses-ribeirinhos terem acesso ao crédito, a agência do banco que operacionaliza essa política pública, encaminha o responsável técnico para georreferenciamento e posterior avaliação técnica da UPF. Visando o manejo do açaí, a aprovação do crédito se deu de forma mais facilitada às UPF que disponibilizavam maior área de floresta. Após a aprovação pelo Banco, os valores financiados variaram proporcionalmente aos tamanhos das propriedades e projeto desenvolvido. Na fase inicial de implantação dos açaizais, o Banco encaminhou o responsável técnico para prestar orientações sobre os procedimentos de manejo das novas áreas destinadas aos açaizais, o que aconteceu de forma desconectada com o contexto, como indica um dos entrevistados: “O técnico que veio nos ensinar no manejo, me orientou a derrubar os açaizeiros nativos e replantar em fileira, na área onde aderir a orientação, só deu problema, até hoje eu devo pro Banco" (Camponêsribeirinho, 60 anos, Guajará de Baixo, set/2020).

Resque e Silva (2017), ao pesquisarem sustentabilidade multidimensional de agroecossistemas familiares em uma comunidade de várzea, no município de Cametá-PA, identificaram que as UPF que tiveram acesso ao PRONAF apresentaram elementos de insustentabilidade ambiental, social e técnico-econômico, como o endividamento e redução na diversidade. Em Guajará de Baixo, a principal causa do endividamento no Banco, dos ribeirinhos que

\footnotetext{
${ }^{6}$ Estuário de várzea, à margem dos rios e igarapés, onde se localiza as residências dos camponeses-ribeirinhos. 
acessaram o PRONAF, foi motivado pela baixa produtividade e perda da qualidade do açaí, que secava nas áreas de açaizais sem vegetação arbórea. Segundo Ploeg (2008), os modelos de agricultura baseados no monocultivo são impulsionados diretamente pelos Impérios Alimentares, que demandam produção em larga escala para atender as redes de empresas globais. Entre os anos de 2000 e 2020, $31 \%$ dos açaizais envolvidos nessa pesquisa sofreram mudanças significativas, indo de um sistema diversificado e sombreado para um monocultivo e, portanto, desprovido de sombreamento para as palmeiras.

Essas constatações reforçam que a homogeneização das práticas impulsionadas pelos Impérios Agroalimentares torna-se falível, quando os pacotes tecnológicos, criados em 'laboratórios', pouco se articulam com as particularidades da realidade local, gerando desconhecimento técnico de uma complexidade totalmente diferente do dito 'laboratório'. Na Ilha Guajará de Baixo, considera-se que a intensificação das práticas de manejo nos açaizais atrela-se à articulação dos camponesesribeirinhos com os intermediários representantes dos empresários, proprietários de redes de empresas exportadoras da polpa do fruto, que necessitam de uma demanda elevada de produção para operacionalização das agroindústrias.

No caso dos açaizais com pouca sombra, a comercialização do açaí acontece exclusivamente para os intermediários. Nas entrevistas, essas famílias alegaram buscar níveis mais elevados de produção para atender à demanda dos intermediários. Segundo um intermediário, atuante na compra de açaí na Ilha Guajará, desde 2006, ao referir-se a três UPF que lhe fornecem a produção de açaí constantemente, e consequentemente cujos açaizais constituem-se em pouca sombra, diz o seguinte:

Esses produtores vendem só pra nós [intermediários], se eles levarem para a feira, ou para as batedeiras, esses não compram, porque o açaí desses açaizais dificilmente fica bem preto, além do que a gente vê que o caroço é seco [contém pouca polpa]. Eu compro, pois a fábrica [agroindústria de açaí] pra onde eu mando a produção, não exige tanta qualidade, eles querem que a gente mande em grande quantidade (Intermediário, 48 anos, Guajará de Baixo, CametáPA, set/2020).

Ressalta-se que um camponês-ribeirinho que já teve experiências com açaizal pouca sombra, e hoje produz em média sombra, compreende que o sombreamento interfere na qualidade do fruto e, sobretudo, na dinâmica dos canais de comercialização a serem acessados para a venda do açaí. Observa-se no trecho de entrevista:

O açaí não é do lavrado, o açaí não é do campo aberto, o que acontece hoje é que em muitos terrenos está só açaizal, e o açaí perde a qualidade por causa disso, muitas vezes o produtor não consegue vender por um preço bom. O açaí do mato do produto X ninguém quer comprar o açaí dele, porque é um açaí seco, ele derrubou todas árvores do mato e o açaí não presta, ele seca antes de pretar. Agora vai nessas outras ilhas onde eles deixam o miritizeiro pra fazer a sombra no mato, lá o açaí fica tuíra mas num seca. Ai amplia mais as opções de mercado, se tu levar na feira tu vende, se tu levar nas batedeiras, os batedores compram, aí tu não fica refém do intermediário (Camponês-ribeirinho, 34 anos, Guajará de Baixo, Cametá-PA, set/2020). 
Ademais, os camponeses-ribeirinhos que mantêm vínculo com intermediário e batedeiras são exclusivamente os que possuem açaizais na escala muita sombra. Nesse caso, a preferência na venda dá-se nas batedeiras, apenas o excedente é vendido ao intermediário, materializando-se os espaços de manobra nos canais de comercialização local de cadeia curta. Segundo esses camponeses-ribeirinhos, nas batedeiras há bastante exigências na qualidade do fruto, dando preferência ao açaí de área sombreada, pois são vistos como açaí de alta qualidade. As famílias afirmam que nesses frutos concentra-se maior quantidade de polpa, obtendo melhor rendimento no despolpamento.

Para Ploeg (2008), o tipo camponês de agricultura está vinculado ao aumento do valor agregado, exatamente o que pode ser verificado como busca entre tais camponeses-ribeirinhos que detêm áreas de muita sombra. Ao invés da abertura de novas áreas para o cultivo, esses camponeses enfrentam o ambiente hostil do sistema capitalista por meio da geração mais autônoma de renda no curto, médio e longo prazo. Percebe-se o efeito do sombreamento como estratégia de aumento do valor agregado na produção de açaí em açaizais, na escala muita sombra. Ademais, a diversidade produtiva gera produtos durante todo o ano.

Observou-se ainda que as famílias que acessaram os três canais de comercialização são as mesmas que possuem escalas de sombreamento média sombra e muita sombra nos açaizais. Salientase que essas famílias são as que mais possuem autonomia e espaço de manobra. Nesse caso, o acesso a mais de um canal é observado como os "espaço de manobra” constituído por tais camponeses. Nas UPF do tipo de agricultura camponesa, $87 \%$ dos entrevistados nunca tiveram acesso a palestras ou cursos sobre manejo de açaizal. Entretanto, as trocas de conhecimentos entre vizinhos e parentes, e nas experimentações realizadas pelos camponeses-ribeirinhos em suas UPF, vêm impulsionando as reflexões críticas acerca das limitações na tomada de decisão sobre o manejo intensivo do ecossistema para a produção de açaí.

Ressalta-se que os reflexos da pandemia da Covid-19 provocaram alterações na dinâmica local de comercialização. Entre os meses de março a dezembro de 2020, em virtude das medidas de biossegurança, as feiras das vilas circunvizinhas foram suspensas, e, junto com elas, a comercialização do açaí. No entanto, a comercialização nas batedeiras e intermediários permaneceram ativa. Especificamente sobre a comercialização do açaí nas batedeiras locais, essa funcionou por encomenda, semelhante ao delivery, de maneira que os donos dos estabelecimentos contatam os camponeses-ribeirinhos e realizam o agendamento do dia e hora de entrega dos frutos por estes, além de combinarem previamente o preço e quantidade a ser entregue do fruto. No caso do intermediário, este não foi afetado. No entanto, segundo os camponeses-ribeirinhos, eram poucos os intermediários que adotavam as medidas de biossegurança, como o uso de máscara, álcool em gel e distanciamento social - fator que pode ter influenciado nos vários casos de transmissão da Covid-19 que assolaram a comunidade no período da safra do açaí. 


\section{CONSIDERAÇÕES FINAIS}

Desde o período de ocupação do ecossistema de várzea amazônica, os camponeses-ribeirinhos empregam práticas no manejo do ecossistema, com maior intensificação da intervenção humana em produtos voltados para os mercados. Para a comercialização do açaí na Ilha Guajará de Baixo, foi constatado que esses camponeses acessam os canais regionais de comercialização, como batedeiras e feiras, mas também canais de cadeia mais longa, nos quais o papel dos intermediários se mostrou preponderante. A expansão dos açaizais em todas as UPF teve início a partir do ano 2000, e a maior intensificação de manejo, alguns anos depois, em 2006. A intensificação no manejo e sombreamento dos açaizais foi motivada justamente pelas mudanças decorrentes da demanda de açaí, sobretudo no que se referiu ao aumento da demanda pelos intermediários. O acesso ao PRONAF por alguns dos camponeses-ribeirinhos se mostrou ingrediente impulsionador desses processos de transformação, e também de consequências de endividamento a esses agricultores.

A partir da mobilização das escalas de sombreamento para compreensão da realidade das UPF da Ilha, pôde-se verificar que, nos açaizais que atualmente se encontram na escala pouca sombra, os camponeses-ribeirinhos são totalmente dependentes do envolvimento do intermediário no processo de comercialização. Nos açaizais com escala média sombra e muita sombra, os "espaços de manobra" são construídos com o acesso aos canais regionais de cadeia curta.

O preço mais elevado para a comercialização do açaí é alcançado nas batedeiras que preferem o açaí proveniente de sistemas com muita sombra, que propiciam a formação de frutos de maior qualidade. Partindo-se da base teórica dos tipos de agricultura, constatou-se estratégias delineadas pelos camponeses-ribeirinhos na adoção de práticas de manejo dos açaizais atreladas ao tipo de agricultura empresarial e camponesa. Ao passo que é possível entender que os camponesesribeirinhos que detêm açaizal em escala pouca sombra, que tiveram acesso ao PRONAF e acessam exclusivamente o intermediário, vinculam-se ao tipo de agricultura empresarial. Por outro lado, os camponeses-ribeirinhos com açaizais em escala média sombra e muita sombra empregam práticas da agricultura camponesa. Nesse caso em específico, essa relação se dá inclusive justificada pela significativa importância que a coprodução e o capital ecológico ganham no manejo do ecossistema e pela estratégia de acesso aos distintos canais de comercialização. Embora o acesso via intermediário seja percebido como uma conquista para os camponeses-ribeirinhos, a magnitude desse canal de comercialização impulsiona as práticas de manejo intensivo nos açaizais.

A pandemia da Covid-19 afetou diretamente a comercialização nas feiras, devido à suspenção de sua realização. No entanto, a comercialização via intermediários se manteve ativa. $\mathrm{O}$ acesso dos camponeses-ribeirinhos aos canais regionais de comercialização do açaí parece contribuir para a permanência do emprego das práticas sustentáveis que mais se articulam ao tipo de agricultura 
camponesa, enquanto que as facetas dominantes dos mercados globais atrelados ao tipo de agricultura empresarial ou capitalista, visando primordialmente a produção em massa, mostram um desprendimento com os princípios de coprodução e coevolução com a natureza.

A abordagem teórico-metodológica dos tipos ideais de agricultura mencionadas por Jan Douwe van der Ploeg apresenta-se como potencialidade para a análise das configurações dos açaizais e das reações e estratégias dos camponeses-ribeirinhos na Ilha Guajará de Baixo, em face às mudanças dos mercados consumidores. Assim, vale mencionar que esse estudo abre importantes janelas de oportunidades para investigações acerca de reações e estratégias camponesas relacionadas a mercados diversos, como aqueles que envolvem emblematicamente a região amazônica, como a soja, o dendê ou mesmo a pecuária.

\section{REFERÊNCIAS}

ARAÚJO, C. T. D.; NAVEGANTES-ALVES, L. F. Do extrativismo ao cultivo intensivo de açaizeiro (Euterpe oleracea Mart.) no estuário amazônico: sistemas de manejo e suas implicações sobre a diversidade de espécies arbóreas. Rev. Bras. de Agroecologia. 10(1): 12-23 (2015).

AZEVEDO, J. R. Sistema de manejo de açaizais nativos praticados por ribeirinhos. São Luis/MA: EDUFMA, p. 100, 2010.

BALDIN, N.; MUNHOZ, E. M. B. SNOWBALL (BOLA DE NEVE): Uma Técnica Metodológica para Pesquisa em Educação Ambiental Comunitária. In: CONGRESSO NACIONAL DE EDUCAÇÃO - EDUCERE, X, 2011, Curitiba. Anais... p. 329 - 241. Disponível em:

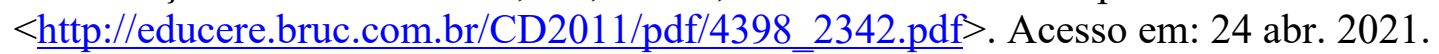

BRONDÍZIO, E. S. The Amazonian Caboclo and the Açaí Palm: Forest Farmers in the Global Market. Advances in Economic Botany, v. 16, p. 387-403, 2008.

CORREAA, R. B. Do território recurso ao território abrigo: Modo de vida e processo de valorização do açaí no município de Cametá- Pa. Boletim Amazônico de Geografia, Belém, v. 01, n. 02, p. 01-14 jul./dez.2014.

CORRÊA, R. B. Território e desenvolvimento: análise da produção de açaí na região Tocantina (PA). São Paulo, 2017. 208f. Tese (Doutorado em Geografia) - Faculdade de Geografia - UNESP, 2017.

CRUZ, M. J. M. Territorialização camponesa na várzea da Amazônia. 274 p. São Paulo, 2007. $272 f$. Tese (Doutorado em Geografia Humana) - Faculdade de Geografia - USP, 2007.

GONZÁLEZ, M. O. Conocimiento local y decisiones de los productores de Alto Beni, Bolivia, sobre el diseño y manejo de la sombra en sus cacaotales. 2006. 76f. Dissertação (Mestrado el Desarrollo y La Conservación) - Centro Agronómico Tropical de Investigación y Enseñanza. Turrialba, 2006.

GROSSMANN, M. et al. Planejamento participativo visando a um manejo sustentável dos açaizais amazônicos e regulamentações oficiais. In: JARDIM, M. A. G.; MOURÃ̃O, L. GROSSMANN, M. (Ed.). Açaí: possibilidades e limites para o desenvolvimento sustentável no estuário amazônico. Belém: Museu Paraense Emílio Goeldi, p. 123 - 134, 2004.

HOMMA, A. K. O. et al. Açaí: novos desafios e tendências. Embrapa Amazônia Oriental-Artigo em periódico indexado (ALICE), 2006. 
HOMMA, A. K. O. Extrativismo vegetal ou plantio: qual a opção para a Amazônia?. Estudos avançados, v. 26, n. 74, p. 167-186, 2012.

MEDEIROS, M. Sendas da sustentabilidade no desenvolvimento rural: os passos e os percalços da construção de um novo código sociotécnico. Florianópolis-SC, 2017. 332f. Tese (Doutorado em Agroecossistemas) - Faculdade de Desenvolvimento Rural- UFSC, 2017.

MENDONÇA, M. S de. et al. Etnobotânica e o saber tradicional. In: FRAXE, T. J P.; PEREIRA, H. S.; WITKOSKI, A. C. (org.). Comunidades ribeirinhas amazônicas modos de vida e uso dos recursos naturais. EDUA - Editora da Universidade Federal do Amazonas. Manaus-Amazonas, 2007.

MICHELAT, G. Sobre a utilização da entrevista não-diretiva em sociologia. In: THIOLLENT, M. (Org.). Crítica metodológica, investigação social e enquete operária. São Paulo: Editora Polis, p. 191-211. 1987.

PAM- Pesquisa Agrícola Municipal. Disponível em: >https://sidra.ibge.gov.br/pesquisa/pam<. Acesso em: 10 jul. 2021.

PEREIRA, M. S.; WITKOSKI, A. C. Construção de paisagem, espaço e lugar na várzea do rio Solimões-Amazonas. Novos Cadernos NAEA, v. 15, n. 1, p. 273-290. 2012.

PETERSEN, P.; DAL SOGLIO, F. K.; CAPORAL, F. R. A construção de uma Ciência a serviço do campesinato. In: PETERSEN, P. Agricultura familiar camponesa na construção do futuro. Rio de Janeiro: AS-PTA, p. 85-104. 2009.

PLOEG, J. D. Van der. Camponeses e Impérios Alimentares; lutas por autonomia e sustentabilidade na era da globalicação. UFRGS Editora, 2008.

PLOEG, J. D. Van der. El proceso de trabajo agrícola y la mercantilización. In: GUZMAN, E. S. (Ed.). Ecologia, campesinato y historia. Madrid: Las Ediciones de la Piqueta, 1992.

PLOEG, J. D. van der. O modo de produção camponês revisitado. In: SCHNEIDER, S. A diversidade da agricultura familiar. Porto Alegre: UFRGS, p. 13-56. 2006a.

PLOEG, J. D. Van der. Sete teses sobre a agricultura camponesa. In: Agricultura familiar camponesa na construção do futuro. AS-PTA. Rio de Janeiro, p. 17-31. 2008.

PLOEG, J. D. Van der. The virtual farmer: past, present and future of the Dutch peasantry. Uitgeverij Van Gorcum, 2003.

REAL, L. C. V.; SCHNEIDER, S. O uso de programas públicos de alimentação na reaproximação do pequeno produtor com o consumidor: o caso do programa de alimentação escolar. Revista Estudo \& Debate, v. 18, n. 2, p. 57-79. 2011.

RESQUE, A G L.; SILVA, L. M. S. Sustentabilidade de agroecossistemas familiares em comunidade de várzea localizada no município de Cametá, estado do Pará. Agricultura Familiar: Pesquisa, Formação e Desenvolvimento, v. 11, n. 1, p. 103-118, 2017.

ROSSET, P. M.; ALTIERI, M. A. Agroecology versus input substitution: A fundamental contradiction of sustainable agriculture. Society \& Natural Resources, v. 10, n. 3, p. 283-295, 1997.

SANTOS, J. C dos.; SENA, AL dos S.; HOMMA, A. K. O. Viabilidade econômica do manejo de açaizais no estuário amazônico: estudo de caso na região do Rio Tauerá-açu, Abaetetuba-estado do Pará. In: Embrapa Amazônia Oriental-Artigo em anais de congresso (ALICE). In: CONGRESSO DA SOCIEDADE BRASILEIRA DE ECONOMIA, ADMINISTRAÇÃO E SOCIOLOGIA RURAL, 50. 2012, Vitória. Agricultura e desenvolvimento rural com sustentabilidade: Anais. Vitória: SOBER: UFES, 2012. 
SCHNEIDER, S.; NIEDERLE, P. A. Agricultura familiar e teoria social: a diversidade das formas familiares de produção na agricultura. In: Embrapa Cerrados. Savanas: desafios e estratégias para o equilíbrio entre sociedade, agronegócio e recursos naturais. Planaltina/DF. p. 989-1014, 2008.

SILVA, M. A. P da.; MALHEIRO, B. C. P.; RIBEIRO, R. A face ribeirinha da orla fluvial de Belém: espaços de (sobre) vivência na diferença. Belém: a cidade e o rio na Amazônia. Belém: EDUFPA, p. 145-169, 2005.

SOBRINHO, S. A. S. A certificação do açaí na região. Riquezas, v. 2, p. 23-30, 2005. 